\title{
Paulo: a anti-escravidão e libertação à luz da carta a Filemon
}

\author{
Paul: the anti-slavery \\ and freedom in the light of the letter to Philemon
}

Isidoro Mazzarolo

\section{Resumo}

A liberdade, distinta da libertinagem, é um paradigma cristão. Jesus não se submeteu aos parâmetros dos costumes da cultura de seu tempo, mesmo respeitando muitos elementos importantes da cultura e religiosidade judaicas ou helenísticas. A carta de Paulo a Filemon é uma demonstração de que os cristãos haviam entendido essa pedagogia da libertação e da dignidade do ser humano, antes e acima de qualquer Lei. Paulo se torna um dos primeiros cristãos a promover a libertação da Lei, da circuncisão e das diversas formas de escravidão.

Palavras-chave: Teologia Paulina. Liberdade. Libertação. Cristianismo. Direitos Humanos.

\section{Abstract}

Freedom, as opposed to debauchery, is a Christian paradigm. Jesus did not subject himself to the cultural parameters of his time, despite having respected many important elements of the Jewish and Hellenistic culture and religion. Paul's letter to Philemon is evidence that Christians had understood this liberation and human dignity pedagogy, above and beyond any Law. Paul becomes one of the first Christians to promote freedom from the Law, circumcision, and from different forms of slavery. 
Keywords: Pauline Theology. Freedom. Liberation. Christianity. Human Rights.

\section{Introdução}

A carta a Filemon é uma das duas únicas cartas verdadeiramente pessoais no NT. A outra é a 3Jo, que também tem um estilo semelhante, a qual é dirigida ao "ancião" pelo seu amigo Gaio ("O ancião ao caríssimo Gaio", 3Jo 1,1), mas o receptor não é explícito, ou seja, quem é esse ancião. ${ }^{1}$ Nas duas cartas, temos uma pessoa que emite e outra que recebe. Nas outras cartas autênticas de Paulo, ele sempre escreve em conjunto com Timóteo ou Silas e os destinatários sempre são grupos, Igrejas ou regiões. Filemon é uma carta que revela a psicologia do maior ao menor, ou seja, de quem tem ascendência espiritual sobre quem é obra dessa espiritualidade. Filemon é um fruto do Evangelho anunciado por Paulo ${ }^{2}$. Revestida de toda uma linguagem afetuosa e cordial. Paulo usa da ascensão que goza em relação a Onésimo, pois o "gerou" na prisão, sendo, por isso, seu pai no Evangelho e, ao mesmo tempo, em relação a Filemon. Quanto a Filemon, este também havia sido convertido por ele, algum tempo antes (v. 19).

Esta é a única carta autêntica de Paulo com o estilo pessoal. ${ }^{3}$ No mundo greco-romano encontram-se muitos exemplos similares, mas dentro do contexto bíblico é a única. Pode-se dizer que Filemon segue muito de perto o estilo das cartas pessoais greco-romanas, mas que não tinham uma finalidade restrita, e sim pública, pois deviam ser lidas em público. ${ }^{4} \mathrm{Na}$ época, a dificuldade de encontrar e obter material para escrever era grande e, não raro, os que recebiam uma carta pessoal era porque se tornavam os leitores ou transmissores da mesma, conforme a primeira bem-aventurança do Ap 1,3: "Bem-aventurado o que lê (reconhece o escrito) e bem-aventurados os que escutam as palavras

\footnotetext{
${ }^{1}$ BRUCE, F. F. The Epistles to the Colossians, to Philemon and to the Ephesians. Michigan: William B. Eerdmans Publishing Company, 1984, p. 191.

${ }^{2}$ MAZZAROLO, I. Filemon, a Carta da Alforria. Rio de Janeiro: Mazzarolo editor, 2011, p. 21.

${ }^{3}$ RUPRPECHT, A. "Philemon". In: THE EXPOSITOR'S BIBLE COMMENTARY WITH THE NEW INTERNATIONAL VERSION. Ephesians trough Philemon. Michigan: Zondervan, 1981, p. 456.

${ }^{4}$ RYAN, J. M. "Philemon”. In: THURSTON, B. B.; RYAN, J. M.; JUDITH, M. Philippians \& Philemon. Minessota: D. J. Harrington editor, 2004, p. 216.
} 
da profecia e guardam o que nela está escrito, o tempo está próximo". Havia a necessidade de alguém que soubesse ler, portanto reconhecer o que estava escrito, e depois pudesse fazê-lo em público. Por isso, era bem-aventurado o que soubesse ler e interpretar e também os ouvintes que conseguissem entender o que tinha sido lido. Essa era também uma prática para tornar conhecidos contratos, acordos, compromissos, etc. que fossem do interesse comum.

A carta a Filemon tem um estilo pessoal, personalizado, semelhante às outras duas cartas (1 e 2Tm), ainda que estas sejam consideradas deuteropaulinas: Paulo, apóstolo de Cristo Jesus... a Timóteo, meu verdadeiro filho na fé (1Tm 1,1-2); Paulo, apóstolo de Cristo Jesus ... a Timóteo, meu filho amado (2Tm 1,1-2). Também podemos acrescentar no mesmo estilo Colossenses ( $\mathrm{Cl}$ 1,1: "Paulo, por vontade de Cristo, ao irmão Timóteo"). ${ }^{5}$ Essas duas cartas, com estilo muito particular ou pessoal, foram das poucas que sobreviveram. ${ }^{6}$ Vielhauer afirma que Fm é a única carta autenticamente paulina destinada a uma pessoa em particular. ${ }^{7}$ Um fato curioso é que, não obstante tão personalizada, ela seja considerada uma carta pastoral por envolver a Igreja doméstica na casa de Filemon: "à Igreja que se reúne em tua casa" (v.2). As Cartas Pastorais tratam de questões abertas, comuns, e podem circular para diversas comunidades. As cartas pessoais se destinam a pessoas e assuntos particulares. Esta, envolvendo três pessoas - Paulo, Filemon e Onésimo -, não se restringe a eles três, mas engloba a Igreja que se reúne na casa dele e o problema dos escravos numa comunidade que abraçou o Evangelho. Para muitos autores, Paulo utiliza, nesse bilhete, uma retórica já conhecida no mundo greco-romano, como por exemplo algumas cartas de Plínio a seu amigo Sabiniano, ao qual pede uma acolhida fraterna de um escravo. Em outra carta, Plínio agradece Sabiniano por ter procedido benevolentemente para com o escravo, acatando as orientações do amigo. ${ }^{8}$

Podemos aceitar que Paulo tenha encontrado em Plínio alguns argumentos de estilo retórico para interceder pelo escravo Onésimo. No entanto, Paulo tinha não apenas argumentos sociológicos ou éticos, mas, sobretudo os princípios do Evangelho. É a partir da fé que a libertação se torna imperativa.

\footnotetext{
${ }^{5}$ MAZZAROLO, I. Filemon, a Carta da Alforria, p. 21.

${ }^{6}$ OSIEK, C. Philippians and Philemon. Nashville: Abingdon Press, 2000, p. 125.

${ }^{7}$ VIELHAUER, P. História da literatura cristã primitiva; introdução ao Novo Testamento, aos apócrifos e aso pais apostólicos. Santo André: Academia Cristã, 2005, p. 202.

${ }^{8}$ BARBAGliO, G. As cartas de Paulo II - Gálatas, Romanos, Filipenses e Filemon. São Paulo: Loyola, 1991, p. 418.
} 
A escravidão era comum e legitimada por leis injustas, mas aplicadas com rigor como direitos dos grandes, nessa época, não só no Império Romano, mas também no judaísmo e outras culturas. No caso de Onésimo, Paulo transformou essa orientação personalizada em uma questão aberta: válida para toda a Igreja de Colossos. A conotação de pastoral pode ser entendida em função da posição de Paulo em torno do assunto dos escravos e sua orientação a Filemon, chefe ou responsável pela Igreja de Colossos.

Uma carta pessoal com endereço público: A carta tem um estilo pessoal, mas uma finalidade pública. Quatro pontos podem ser destacados para isso: ${ }^{9}$

a. O grande número de elementos jurídicos que a carta contém, não envolvendo apenas Filemon, mas as outras pessoas da comunidade;

b. Onésimo, escravo até encontrar Paulo, não seria um fugitivo, mas enviado a Paulo por causa da Igreja de Colossos;

c. Paulo escreve a fim de que Onésimo seja deixado livre para trabalhar na Igreja de Colossos. Onésimo não é o portador da carta para Filemon;

d. Paulo espera que Onésimo seja investido dessa nova tarefa.

Quanto aos aspectos "b" e "d", são muito discutidos. São poucos os autores que acreditam que Onésimo seja um escravo de Arquipo e não de Filemon. A carta não deixa clara a nova missão de Onésimo em Colossos, mas esclarece a necessidade de considerá-lo livre, porque foi libertado na prisão por Paulo. Se Onésimo fosse escravo de Arquipo a carta seria dirigida a ele e não para Filemon. A opinião de que Onésimo não seria um fugitivo, mas um escravo que foi até a prisão, onde Paulo estava, com uma missão específica da Igreja de Colossos, pode ser verdadeira; isso poderia explicar de modo mais simples o encontro dele com Paulo, mas dificultaria, ao menos em parte, a necessidade de uma carta tão exigente a Filemon no seu retorno. Barbaglio acredita que Onésimo poderia ter fugido da casa de Filemon e, sabendo da ascendência de Paulo, o teria procurado na prisão em busca de apoio. ${ }^{10}$

\footnotetext{
${ }^{9}$ Cf. OSIEK, C. Philippians and Philemon, p. 129, apresentando um estudo de Sara Winter e Knox (1959).

${ }^{10}$ BARBAGLIO, G. As cartas de Paulo II, p. 419.
} 


\section{A escravidão no judaísmo antigo}

A escravidão era uma realidade comum na antiguidade. Os escravos não tinham muitas escolhas. A grande maioria nascia e morria como escravo. A fuga era uma possibilidade de libertação, mas os riscos poderiam ser fatais, se descobertos e devolvidos aos seus antigos donos. As circunstâncias em que Onésimo encontra Paulo são desconhecidas, mas o que acontece é a mudança no retorno: ele não é devolvido como escravo para ser castigado, mas como livre (Fm 8-10).

No mundo judaico, havia diferentes formas de escravidão, mas a mais comum era ter pessoas submissas, sem liberdade e sem direitos, como posse. Havia escravos nascidos de famílias já confinadas, escravos comprados (Ex $12,44 ; 21,2)$ e escravizados como espólios de guerras. Quanto aos escravos comprados, eles seriam propriedade da casa e deixados como herança para os filhos (Lv 25,44-46).

No Império Romano, a violência e a falta de liberdade, especialmente para os não romanos, eram o quotidiano. Os seis séculos de pax romana não foram mais que tempos duros de sofrimento e serviço para o sistema militar-imperial, que consumia os suores das colônias em detrimento de luxo, do poder e dos custos das guerras.

A maior parte dos escravizados no Império Romano eram prisioneiros de guerra ou raptados de suas famílias, levados para longe de sua terra de origem. O sistema escravagista era uma grande base da economia e conferia honra e status aos conquistadores. ${ }^{11}$ Muitas vezes, depois das conquistas, criavam-se classes de escravos, onde os seus possuidores se colocavam como seus protetores e defensores, dando-lhes segurança e sustento em troca do serviço e da submissão. Mesmo que pudesse haver escravos internos, isto é, cidadãos tomados como penhora de dívidas ou contratos, a grande maioria, quer no mundo judaico, quer no universo greco-romano, era de estrangeiros. ${ }^{12}$

Os escravos e as escravas que tiverdes deverão vir das nações que vos circundam; delas podereis adquirir servos e servas. Também podereis adquiri-los dentre os filhos dos hóspedes que habitam entre vós, bem como das suas famílias que vivem convosco e que nasceram na vossa terra: serão

\footnotetext{
${ }^{11}$ RYAN, J. M. "Philemon", p. 170.

${ }^{12}$ Historiadores estimam que para construir os principais edifícios de Roma, dentre eles, o Coliseu, tenham sido trazidos das colônias cerca de 500 mil escravos.
} 


\begin{abstract}
vossa propriedade e deixá-los-eis como herança a vossos filhos depois de vós, para que os possuam como propriedade perpétua. Tê-los-eis como escravos, mas, sobre os vossos irmãos, os israelitas, pessoa alguma exercerá poder de domínio. E se o estrangeiro ou o hóspede que vive contigo se enriquecer e teu irmão que vive junto dele se empobrecer e se vender ao estrangeiro ou ao hóspede ou ao descendente da família de alguém que reside entre vós, gozando do direito de resgate, mesmo depois de vendido, um dos seus irmãos poderá resgatá-lo (Lv 25,44-48).
\end{abstract}

Este e outros textos mostram como os estrangeiros podiam ser escravizados, comprados ou vendidos sem o menor escrúpulo ético. Para que a consciência não acusasse o dolo, a lei servia com anestésico moral. A lei homologava o imoral; por isso, o imoral se tornava legal. Paulo vai se distanciar dessas práticas e vai sustentar que tudo o que é imoral não pode ser considerado legal.

Os escravos e as mulheres eram figuras sem direitos: "Não cobiçarás a casa do teu próximo, a mulher do teu próximo, nem o seu escravo, sua escrava, nem o seu boi, o seu jumento, nem coisa alguma que pertença a teu próximo" (Ex 20,17). Os escravos não só não tinham direitos, como estavam sujeitos, não raro, aos desmandos de seus patrões, os quais detinham direitos absolutos sobre eles. Em casos de fuga ou de revolta, os escravos eram punidos com a morte, mesmo que fossem alguns, alguma centena ou até milhares. ${ }^{13}$

Em Israel, ao menos em teoria, os escravos tinham algumas leis a seu favor. A primeira era o direito ao repouso sabático (Ex 20,10). Havia uma diferença muito grande de tratamento entre o escravo israelita e o escravo estrangeiro. No ano sabático, haveria a remissão de todas as penhoras e dívidas, e isso incluía o escravo, o qual ganharia a liberdade, mas apenas o escravo israelita (Dt 15,1-2). Na prática pode-se questionar se isso acontecia. O estrangeiro escravizado poderia continuar sendo explorado, sem levar em consideração o direito de liberdade depois dos seis anos, porque essa lei valia somente para o "próximo e o irmão" de raça - sempre considerando o ambiente israelita, não o estrangeiro (Dt 15,5). "Quando um dos teus irmãos hebreu ou hebreia for vendido a ti, ele te servirá por seis anos. No sétimo ano tu o deixarás ir embora livre, e quando o deixares ir embora, não o despeças de mãos vazias; carrega-lhe o ombro com presentes do produto do teu rebanho, da tua eira e do teu lagar" (Dt 15,12-14).

\footnotetext{
${ }^{13}$ RYAN, J. M. "Philemon", p. 170, citando TÁCITO. Ann. 14.43.4, citado por BRADERLEY. Slaves and Masters, I, pp. 15-16.
} 
Mesmo com a lei da alforria do sétimo ano, a chance de emancipação era quase impossível e, via de regra, dependia do favor ou da graça de uma pessoa livre, como é o caso de Onésimo. Até mesmo se um escravo quisesse casar e constituir família, teria que pagar o que the era estipulado pelo seu senhor. Em caso de impossibilidade de efetuar todo o pagamento no tempo exigido, poderia ver seus filhos vendidos como parte do saldo devedor. ${ }^{14}$ Por isso, a fuga era a única via de esperança para alcançar a liberdade, mesmo assumindo todos os riscos que poderiam advir dela.

Nos antigos santuários havia muitos empregados dos sacerdotes e dos serviços religiosos dos templos que trabalhavam como escravos. No templo de Karnac, no médio Egito, não só os milhares que o construíram eram escravos, mas as centenas que trabalhavam em sua manutenção eram escravos domésticos do serviço religioso. O mesmo se pode dizer do templo da Grande Ártemis, em Éfeso, para o qual, segundo alguns autores, Onésimo teria fugido. Mas essa hipótese carece de consistência devido à referência de Paulo que afirma tê-lo "gerado" na prisão (v. 10).

A troca, compra e venda de escravos era bastante comum nas culturas antigas. As possibilidades de alcançar a liberdade eram muito parcas e remotas, mesmo que algumas vezes isso fosse possível. Ainda que um decreto de $\mathrm{Au}-$ gusto estipulasse uma data de trinta anos como limite máximo, para alguém ser escravo e depois ser liberto, as condições não mudavam muito. ${ }^{15}$

\section{As prisões no contexto do Império Romano}

A expansão do império e as conquistas dos territórios dominados geravam muitas revoltas. O império crescia e se impunha pela força e pela violência. Muitos prisioneiros eram transformados em escravos, comercializados entre homens ricos ou mesmo enviados a Roma para trabalhar como escravos nas construções da cidade.

As prisões tinham duas finalidades: a. A primeira era trancafiar bandidos, revoltosos e criminosos. Essa era a finalidade precípua de uma carceragem, como continua sendo nos tempos atuais; b. A segunda era para proteger elementos em perigo de morte, como é o caso de Paulo, em sua última estada em Jerusalém. Diante das ameaças de morte dos judeus, o Tribuno romano, em

\footnotetext{
${ }^{14}$ RYAN, J. M. "Philemon”, p. 171, citando BRADERLEY. Slaves and Masters, pp. 79-80.

${ }^{15}$ RYAN, J. M. "Philemon”, citando BRADERLEY. Slaves and Masters, pp. 84.86, n. 19, referente à informação de SUETÔNIO. Aug. 21,2.
} 
Jerusalém, providencia uma escolta para conduzir Paulo até Felix, na Cesareia Marítima, onde ficaria, numa prisão condicional, a salvo dos judeus (At 23,2324). Paulo teve esse privilégio da proteção militar por ser cidadão romano.

Paulo fala que esteve mais vezes em prisões (2Cor 11,23). Essas prisões podiam acontecer em diferentes situações: a. Uma primeira situação era realizada em barracas ou acampamentos no campo de prisão ou de proteção transitória, nos campos de batalha; b. Uma segunda situação era a domiciliar, onde o inquirido ficava na própria casa, mas com a guarda romana, que o protegia ou vigiava; c. Uma terceira situação acontecia em circunstâncias de transferência, quando o prisioneiro era enviado para uma triagem ou processo em Roma (é caso típico da prisão de Paulo em Cesareia Marítima, At 23,23-26,32); d. O quarto aspecto se dava em ocasiões quando os condenados eram sentenciados ao exílio ou simplesmente expulsos do lugar e eram acompanhados até a fronteira ou fora das cidades. As prisões de custódia não podem ser confundidas com as prisões públicas, onde os prisioneiros perdiam a totalidade da liberdade e a custódia dos soldados não era uma proteção, mas o sentido radical da condenação. Segundo Juvenal (entre o $1^{\circ}$ e o $2^{\circ}$ século d.C.): "Felizes os tempos dos reis e tribunos, em que Roma se satisfazia com uma única prisão". ${ }^{16}$ Segundo Tito Lívio, essa prisão era o Marmetino, a mais antiga de Roma, ainda que esse nome só seja dado mais tarde. ${ }^{17}$

Muitas vezes, as prisões não passavam de meros confinamentos de pessoas sem qualquer condição de sobrevivência. As cadeias eram, via de regra, lugares onde a morte por doenças acontecia em virtude das condições em que os prisioneiros eram colocados. As cadeias e as leis em torno de quem deveria ser encarcerado dependiam dos chefes de governo, senhores de escravos ou militares. Um código de Sulla (81 a.C.) escrevia que quem tirasse a vida do outro deveria ser preso. ${ }^{18}$ Dependendo da interpretação do crime, muitos homicidas eram sentenciados com a pena capital, em retribuição à vida que ele havia tirado. ${ }^{19}$

\footnotetext{
${ }^{16}$ RAPSKE, B. Paul in Roman Custody. The Book of Acts in its First Century Setting. Volume 3. Michigan: William B. Eerdmans Publishing Company, 1994, p. 21, citando JUVENAL, 4,313s.

${ }^{17}$ RAPSKE, B. Paul in Roman Custody, citando LIVIO. 34.22.10; 34.44.7; SALLUSTIANO. Cat. 55,2. Cárcere é um termo usado por Ulpiano Dig. 48.3.1, confirmando que Cárcere do Marmetino surge mais tarde.

${ }^{18}$ RAPSKE, B. Paul in Roman Custody, p. 44, citando CÍCERO. Clu. 54.148; 57.157.

${ }^{19}$ HARRILL, J. A. "Paulo e a escravidão". In: SAMPLEY, J. P. Paulo no mundo Greco-Romano, um compêndio. São Paulo: Paulus, 2008, p. 505.
} 
Nem sempre as prisões eram para criminosos ou assassinos. Desde os tempos de Acab, rei de Israel (874-853 a.C.), os que fazem oposição ao regime institucional sofrem perseguições e cadeias (cf. 1Rs 18-19). Mais tarde, no século VII, o profeta Jeremias vai ser feito prisioneiro por Joaquim, no reino de Judá, às vésperas do exílio da Babilônia (Jr 26,7-10).

Assim, quer a nível privado (senhores escravos), quer na macroestrutura dos impérios que fizeram história, as prisões funcionavam muito bem sob o rótulo das ideologias de poder.

No contexto do Império Romano, não obstante todo o avanço do seu Código de Direito Civil, havia uma distinção bastante clara entre os cidadãos, os quais eram considerados membros plenos da comunidade, e os estrangeiros. Para os cidadãos, as leis garantiam uma plenitude de direitos e deveres, pois eles se enquadravam num esquema social de isonomia sócio-política (Paulo e Silas em Filipos, At 16,35-40). Quando um crime acontecia envolvendo mais de uma pessoa, o cidadão romano esperava sempre uma pena mais branda do que o não cidadão. Em qualquer situação de conflitos comerciais, heranças, disputas ou pagamentos de dívidas, também havia distinções técnicas entre os cidadãos romanos e os outros. A Lex Valeria ${ }^{20}$ teria sido a lei mais antiga que garantia ao acusado o direito de apelação. Segundo Lívio, a Lei Valeriana impedia que alguém fosse aprisionado e sequestrado ao longo dos caminhos ou em outras situações que surgissem apenas pelas acusações de alguém. A detenção poderia acontecer, nesse caso, como uma prisão de custódia para averiguar a procedência da queixa-crime.

$\mathrm{O}$ direito de apelação se constitui numa novidade dentro dos quadros jurídicos antigos. No contexto Valeriano, consagrou-se a seguinte expressão: Provoco (provocar ou discordar, desafiar - no direito romano significava apelar); desta forma, todo cidadão acusado poderia contestar gritando: Provoco - Eu apelo. Em seguida, ele gritava: "Eu sou cidadão romano". ${ }^{21}$ Esse foi o recurso usado por Paulo e Silas em Filipos (At 16,16-40) quando foram aprisionados e colocados no fundo da prisão com uma corrente prendendo os pés ao cepo, mas, conhecendo o argumento jurídico da cidadania, eles protestam contra os magistrados, pois como cidadãos romanos não poderiam ter sido presos sem antes ser instaurado um processo.

Os cidadãos romanos tinham determinados privilégios, mesmo na prisão ou quando colocados em prisões domiciliares sob custódia. Na prisão de Éfe-

\footnotetext{
${ }^{20}$ RAPSKE, B. Paul in Roman Custody, p. 48, citando LÍVIO. 10.9.3.

${ }^{21}$ RAPSKE, B. Paul in Roman Custody, p. 50, citando CÍCERO. Verr. 2.1.7; 2.5.140-42.
} 
so Paulo tinha bastante liberdade, pois ao escrever aos Filipenses ele afirma que as suas prisões resultaram em benefício para todo o pretório (F1 1,12-13). De forma análoga na prisão de custódia da Cesaréia Marítima (At 24-26), Paulo goza de amplo direito de defesa diante dos seus acusadores e dos representantes de Roma. As coisas eram muito diferentes para os que não possuíssem cidadania romana.

O Código de Direito Romano deu ao mundo as bases da legislação civil. A possibilidade de ter o eco da voz ouvido pela autoridade era um grande privilégio no contexto dos povos antigos. No entanto, não obstante a existência de uma Lex Valeria, que permitia o direito de defesa, sabe-se que o poder, não raro, se sobrepunha. O surgimento de outra norma, chamada Lex Julia, permitia que as pessoas investidas de poder levassem ou não em conta a provocatio. Conforme Garnsey, muitos imperadores e reis abusaram dos direitos e impuseram muitas pessoas cidadãs e não cidadãs sob um regime de violência, massacres e mortes usando a Lex Julia. ${ }^{22}$

\section{O problema da escravidão e o Cristianismo nascente}

A escravidão, nas sociedades antigas, era um direito dos ricos e nobres e um dever dos que já não tinham direitos desde o nascimento. Uma das referências de Paulo, mais discutidas e conflitivas sobre o tema é 1Cor 7,20-24. Segundo Harrill, especialmente o v.21 é de difícil compreensão e tradução, pois diz: "Eras escravo quando foste chamado? Não te preocupes com isto, mas se podes tornar-te livre, de preferência, usa". ${ }^{23}$ Paulo, neste caso, parece ser conformista com a escravidão, mas isso não é verdade. Ele sabia dos direitos dos donos e, como eles possuíssem direitos de vida ou morte sobre os mesmos, então desaconselha revoltas ou manifestações contra os patrões a fim de evitar massacres. Era mais interessante esperar que o seu patrão alcançasse a conversão e então o processo de libertação se daria sem derramamento de sangue. Harrill, no entanto, acredita que Paulo era conservador no campo social e que assimilava os esquemas sócio-políticos greco-romanos, propenso a exortar os cristãos a permaneceram na condição de escravidão ${ }^{24}$. É pouco

\footnotetext{
${ }^{22}$ RAPSKE, B. Paul in Roman Custody, p. 52, citando GARNSEY. Lex Julia, 169.

${ }^{23}$ HARRILL, J. A. "Paulo e a escravidão". In: SAMPLEY, J. P. Paulo no mundo greco-romano, p. 518.

${ }^{24}$ HARRILL, J. A. "Paulo e a escravidão". In: SAMPLEY, J. P. Paulo no mundo greco-romano, p. 521.
} 
provável que Paulo concordasse com a escravidão; o que é mais lógico é saber que ele não podia, sozinho ou com poucos discípulos, quebrar os grilhões de um Império Romano.

A carta de Paulo a Filemon revela uma preocupação e o começo dos questionamentos em torno da escravidão aos que se convertiam ao Cristianismo. Uma prática tão incrustada pelos "séculos dos séculos" não seria fácil de ser removida. Paulo tinha clareza de que a escravidão feria o Evangelho de modo frontal, e assumiu logo uma posição clara diante dessa questão: Não há mais diferença de escravo e livre, judeu e grego, homem e mulher (G1 3,28). O Evangelho era um único e, não havendo dois, as contradições se tornavam intoleráveis (Gl 1,6-9).

O Cristianismo começa a receber gente rica, nobre, poderosa (cf. personagens como Zaqueu, Levi, Nicodemos, os cristãos de Tessalônica, At 17,4), mas também pobres e escravos, e isso gerava, não raro, dificuldades e tensões na comunidade, pois os mais humildes esperavam encontrar ali um espaço diferencial de libertação, ocasionando reclamações, murmurações, etc. (cf. 1Cor 11,17-27; F1 12-18). As diferentes camadas sociais aspiravam a um clima de maior sintonia e harmonia, ao menos dentro da assembleia: Assembleia Religiosa, por se tratar de uma questão cúltica, mas parece que isso não era muito bem aceito, provavelmente, pelos que tinham uma condição econômica mais favorável. Assim, Paulo vai ter que pedir que as mudanças se processem de modo gradual e cada um considere, inicialmente, o seu lugar (1Cor 7,20).

Há autores que criticam muito essa posição de Paulo (1Cor 7,17-24), considerando que ele é conformista e favorável à manutenção do status quo existente. A opinião desses autores parece não ter muito fundamento, visto que o Apóstolo não tem nada de conformista, mas da mudança gradual e dentro das possibilidades, como é testificado na carta a Filemon. Uma sociedade não se faz de iguais, mas de diferentes, com dons, talentos, carismas e virtudes próprios, independentemente da posição social (1Cor 12,12-30); em segundo lugar, o Evangelho ensina a viver o agápê na diversidade, pois só ele constrói (1Cor 8,1 ), e a liberdade em todos os níveis e circunstâncias, pois é para isso que Cristo nos resgatou (G1 5,1). A escravidão é incompatível com o Evangelho e a libertação se faz com a maturidade humana, a harmonia social e um amor sem hipocrisias (Rm 12,9).

Baseados em outros textos, alguns autores afirmam que diversos textos do NT apoiam uma posição favorável à manutenção da escravidão. Osiek, citando Allen Callahan, afirma que Ef 6,5-8; Cl 3,22-25; 1Tm 6,1-2; Tt 2,9-10; 
1Pe 2,18-25 são textos que provam o "concordismo" da Igreja cristã primitiva com a escravidão. Esse estado de coisas teria permanecido até meados do IV século d.C. ${ }^{25}$ Isso não pode ser dito de Paulo, pois ele tinha clareza da superação desses arquétipos em Jesus Cristo: "É para a liberdade que Cristo nos libertou. Permanecei firmes, portanto, e não vos deixeis prender de novo ao jugo da escravidão" (G1 5,1).

A escravidão era uma realidade cruel e presente em todo o mundo antigo. No período romano a escravidão em massa se acentua em função das guerras e das construções das grandes muralhas das cidades, dos palácios dos reis e nobres e produção de alimentos. A carta a Filemon é uma bela página que demonstra como os primeiros cristãos, em nome do Evangelho, empenhavam-se na luta pela dignidade, liberdade e direitos humanos, contrariando todos os costumes da época, inclusive de pessoas eminentemente religiosas. Paulo, em 1Cor 7,20, orienta para que cada qual permaneça na condição em que foi chamado por Deus, mas isso não significa que ele e o Cristianismo Primitivo eram favoráveis à manutenção da escravidão. A filosofia cristã era de acreditar que a libertação é um processo que não se faz com guerras ou revoltas na comunidade, contra os superiores, líderes ou mais abastados economicamente. Paulo usa a pedagogia do Evangelho, segundo o exemplo de Jesus.

A pedagogia da libertação é uma prática patenteada por Jesus. Quando ele é convidado a uma refeição na casa de Simão, o fariseu, e nela entra uma mulher prostituta ( $\mathrm{Lc}$ 7,36-50), ele se preocupa mais com a mulher do que com o fariseu que o convidou. Jesus não concordava com o tratamento que as práticas semitas davam às mulheres, aos doentes, estrangeiros e órfãos. Nesse episódio na casa de Simão, o fariseu, Jesus quer aparar algumas arestas construídas ao longo dos séculos, mas cristalizadas no judaísmo com a reforma de Esdras (Esd 9-10), no pós-exílio. O fariseu se considerava puro e a mulher era considerada impura. Jesus não estabelece um juízo de valores, apenas se coloca entre dois extremos: Simão era o símbolo da perfeição e a mulher o símbolo da imperfeição, ou seja, um salvo e a outra perdida. Jesus não condena o fariseu, mas provoca a sua conversão através da atenção dedicada à

\footnotetext{
${ }^{25}$ OSIEK, C. Philippians and Philemon, p. 129, citando Allen Callahan (1997). Na bibliografia, Osiek indica dois artigos de Allen Callahan, mas com datas diferentes: 1995a - "Paul's Epistle to Philemon: Toward an Alternative Argumentum" HTR, 86, 357-76; 1995b - "John Chrysostom on Philemon: A Response to Margaret M. Mitchell”, HTR, 88: 149-56. Não é possível saber a qual dos dois artigos citados pertence a referência indicada no texto.
} 
mulher. Enquanto ele dialoga respeitosamente com a mulher, está provocando o fariseu à conversão. ${ }^{26}$

Paulo incentiva a libertação, mas nesse processo, os cristãos precisavam evitar a violência ou a revolta dos escravos contra seus patrões. Vemos nisso as orientações à participação nas Assembleias Eucarísticas (1Cor 11,17-34). O Apóstolo condena a participação nelas de quem pratica injustiças, opressões e tiranias no quotidiano. Sua consciência é clara quanto à incompatibilidade da aproximação da Ceia de quem não vive o agápê do jeito de Jesus (Rm 12,1-3.9). ${ }^{27}$

A carta a Filemon é um marco fundante para o começo das posturas cristãs diante da escravidão. Toda a pedagogia de Jesus, na busca da inclusão dos excluídos, foi a força de ruptura com esquemas escravagistas, mas a carta a Filemon se torna uma referência dentro do Cristianismo primitivo. Ryan afirma que Paulo assume uma postura clara, em nome do Evangelho, na construção de uma sociedade de "irmãos e irmãs". ${ }^{28}$ Filemon mostra como Paulo se posiciona a favor do escravo e faz exortações severas ao seu possuidor (antigo). Ryan cita uma carta de Inácio, bispo da Antioquia da Síria, a Policarpo, bispo de Esmirna, onde ele solicita a Policarpo a providência de dinheiro para criar um fundo econômico para a libertação de escravos (Ign. Pol, 4,3; cf. Smyrn, 6,2). ${ }^{29}$

\section{Paulo e seu contexto de prisões}

No seu relato autobiográfico (2Cor 11,23), Paulo afirma: "São ministros de Cristo? Como insensato, digo - muito mais eu, muito mais pelas fadigas, pelas prisões, infinitamente mais pelos açoites. Muitas vezes me vi em perigo de morte". Outro retrato de sua vida e suas prisões nos é dado em 2 Cor 6,310 , no qual narra o grande número de situações de perigo, não obstante sua identidade de cidadão romano (At 16,37; 22,25).

As prisões não podem ser tomadas apenas com um sentido religioso.

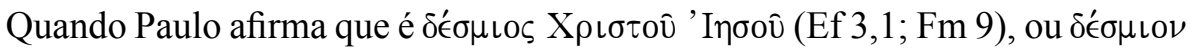

\footnotetext{
${ }^{26}$ MAZZAROLO, I. Lucas, a antropologia da Salvação. Rio de Janeiro: Mazzarolo editor, 2004, pp. 121-124.

${ }^{27}$ MAZZAROLO, I. Carta de Paulo aos Romanos. Rio de Janeiro: Mazzarolo editor: 2006, pp. 247-255.

${ }^{28}$ RYAN, J. M. Philippians and Philemon, p. 195.

${ }^{29}$ RYAN, J. M. Philippians and Philemon, p. 195.
} 


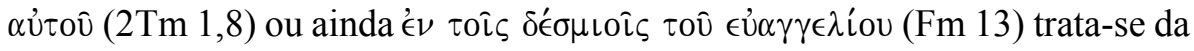
prisão no sentido religioso. ${ }^{30}$ Essa afirmação de Kittel pode ter seus motivos, mas estar preso por causa de Cristo ou por causa do Evangelho não significa, necessariamente, estar numa prisão religiosa ou vocacional a exemplo do profeta Jeremias quando afirma que foi seduzido por Deus (Jr 20,7). Na carta aos Filipenses, Paulo se refere aos benefícios que resultaram para todo o pretório em virtude de sua prisão e da mesma forma o conhecimento de Jesus Cristo dentro do contexto da carceragem (F1 1,12-15). Esse é um caso em que a prisão não pode ser vista no contexto teológico ou metafórico, mas real.

Paulo, não obstante sua cidadania romana, não usava esse privilégio, exceto em caso de perigo fatal, como em Fillipos (At 16,16-24) e em Jerusalém (At 23,27). A cidadania romana era um passaporte que distinguia seu possuidor de outros cidadãos dentro do Império Romano. Era concedido a romanos; descendentes de romanos, mesmo nascidos nas colônias do império, e a quem quisesse comprar. O cidadão romano tinha privilégios diante de situações de conflitos ou possíveis arbitrariedades das autoridades locais; em situações mais delicadas poderia até solicitar escolta até um lugar de proteção, como foi a transferência de Paulo de Jerusalém para a Cesareia Marítima (At 23,23-24). Paulo não era descendente de romanos, mas de judeus, e seu pai havia adquirido esse passaporte, o qual concedia os mesmos direitos aos descendentes diretos, por isso ele o tinha. Entre os primeiros cristãos, ao menos dois tinham esse passaporte de cidadãos romanos: Paulo e Silas (At 16,1637). No aprisionamento de Filipos, Paulo e Silas foram açoitados com varas (At 16,22-24), contrariando a Lex Porcia, que proibia severamente esse tipo de castigo a cidadãos romanos. ${ }^{31}$

Os privilégios da cidadania romana nem sempre valiam, pois muitas vezes o direito era desrespeitado. Paulo só faz uso quando sabe que a autoridade romana lhe dava proteção e em situações de extremo risco de vida. Talvez ele não quisesse mostrar-se diferente de outros que sofriam também por não

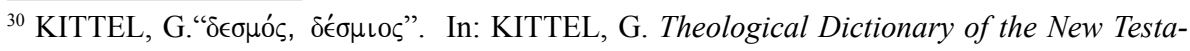
ment. Volume II. Michigan: WM. B. Eerdmans Publishing Company, 2006, p. 43.

${ }^{31}$ As leis Valeriana e Pórcias eram específicas para cidadãos romanos e impediam que eles sofressem punições humilhantes como a flagelação ou a crucifixão. Elas também introduziram o direito de defesa com a apelação aos tribunos da plebe conhecida como "provocatio ad populum". Para uma melhor compreensão da "'provocatio" é melhor separar a palavra latina: pro-vocatio = invocar junto. Não tem o mesmo sentido em português de "provocação". "Provocatio ad populum" é, diante de qualquer dúvida jurídica, a possibilidade de apelar para a opinião popular, isto é, convocar o povo.
} 
terem esse passaporte. Ninguém podia obter a cidadania se não tivesse um nome latino. Assim, poderia ser uma razão para se ter dois ou mais nomes. Quando um estrangeiro ou um escravo era promovido a cidadão pleno, ele assumia o sobrenome de quem lhe havia obtido a promoção. Os dois nomes indicariam a condição explícita do Apóstolo: Saul... - que também se chamava Paulus (At 13,9).

\section{Paulo, o prisioneiro e ancião a Filemon, o amado e colaborador}

A carta a Filemon é a menor de todas as cartas de Paulo, mas não é a que tem menor peso. Paulo, ao interceder por um escravo, que ele "emancipou" na prisão, mostra seu pensamento e sua dignidade humana em favor de todos os que eram excluídos ou marginalizados no seu tempo. Comblin afirma que Paulo desafia Filemon a aceitar Onésimo como irmão associado e a resposta está no próprio "Evangelho" de Paulo, pois com Cristo começa a liberdade para um mundo novo. ${ }^{32}$ Comblin continua afirmando que o "agápe" estava já presente no Antigo Testamento, pois a "Hesed" era a solidariedade baseada nos critérios da raça e do sangue. Nesse ponto, podemos discordar de Comblin, pois o "agápê" cristão não tem relação com a raça e o sangue, mas com a verdade do Evangelho, quando Jesus afirma que seu irmão, irmã, pai ou mãe não são os da sua casa, mas os que fazem a vontade de Deus (cf. Mc 3,31-35). Da mesma forma, Paulo entende que o Evangelho não tem caráter de sangue ou povo, mas da vontade de Deus (G1 3,28; Rm 10,12; C1 3,11). Nesse aspecto é que aplicando à relação "senhor-escravo" a força do Espírito Santo a destrói completamente. ${ }^{33}$ Nesse aspecto, quem quebra a escravidão é a força do Espírito Santo e não a Lei.

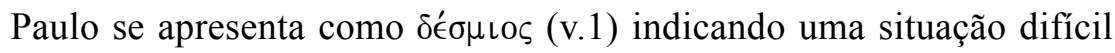
e complicada na sua missão, mesmo que, muitas vezes, as prisões tivessem sido causa de empenho maior dos irmãos no anúncio do Evangelho $(\mathrm{F} 11,14)$ e ele mesmo, nas suas cadeias conseguiu manifestar o Evangelho de Cristo a todo o pretório $(\mathrm{Fl} \mathrm{1,13).} \mathrm{Paulo,} \mathrm{na} \mathrm{condição} \mathrm{de} \mathrm{prisioneiro,} \mathrm{como} \mathrm{auto}$

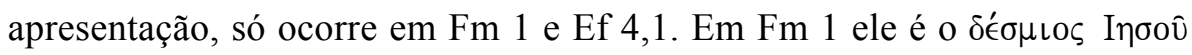
'I a autenticidade paulina de Efésios, observamos que as duas afirmações se

32 COMBLIN, J. “A Mensagem da Epístola de São Paulo a Filemon”. Estudos Bíblicos 2 (1987), p. 53.

${ }^{33}$ COMBLIN, J. “A Mensagem da Epístola de São Paulo a Filemon”, p. 56. 
aproximam muito. Kittel, citando Reitzenstein, acredita que essa terminologia pode estar ligada ao conceito de Mistério, pois a expressão de Fm 13 $\kappa \alpha \tau \in$ $\chi \epsilon \iota \nu$ propõe uma dependência e Paulo olha para sua prisão como uma preparação final para o mistério com Cristo. ${ }^{34} \mathrm{O}$ próprio Kittel afirma que um argumento contra essa posição de Reitzenstein seriam duas afirmações do próprio Apóstolo (F1 2,24; Fm 22).

Estar preso, como ele próprio faz referência aos invejosos e rivais em $\mathrm{Fl}$ 1,15 não era uma questão de dependência teológica ou de Mistério, mas uma questão real. Na perspectiva social era uma vergonha, mas sendo por causa do Evangelho, se transformava em questão de orgulho. "Paulo não usa a expressão prisioneiro de Cristo Jesus em nenhuma outra carta, por isso está claro que se encontra no cárcere". ${ }^{35}$

Outro argumento importante é a idade, pois ele se define como $\pi \rho \in \sigma \beta u ́ t \eta \varsigma$ (v.9) que serve para manifestar a ascensão ou a autoridade de Paulo sobre Fi-

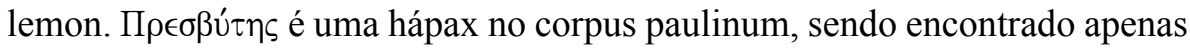
outras duas vezes no NT, em Lc 1,18 referindo-se a Zacarias diante da visão do anjo e em Tt 2,2, no conselho que Tito deve transmitir aos anciãos, a fim

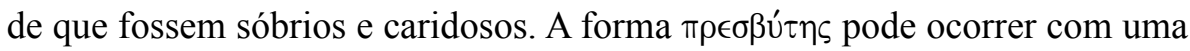
pequena variante, $\pi \rho \in \sigma \beta \in u ́ \tau \eta \varsigma$ (2Cor 5,20; Ef 6,20), com o significado de embaixador $^{36}$.

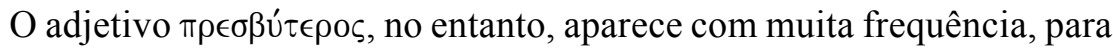
indicar os anciãos de Jerusalém, as hierarquias de Israel e Judá, os membros do Sinédrio e, muitas vezes, as coortes dos juízes ${ }^{37}$. Paulo se dirige a Filemon sem usar argumentos apostólicos ou jurídicos, mas aspectos pessoais, de afeto e autoridade moral e, como Filemon tinha muita estima por Paulo, seu mestre, agora lhe era solicitado o mesmo afeto ao novo filho gerado na prisão, Onésimo.

Filemon é tratado de modo muito afetuoso indicando uma grande pro-

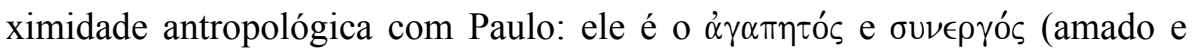

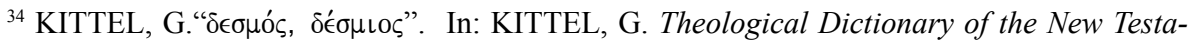
ment. Volume II. Michigan: WM. B. Eerdmans Publishing Company, 2006, p. 43.

${ }^{35}$ GORDAY, P. "Filemon". In: VV. AA. Colossenses, 1-2 Tessalonicenses, 1-2 Timoteo, Tito, Filemón. La Biblia Comentada por los Padres de la Iglesia. Volume 9. Madrid, Bogotá, Buenos Aires, Montevideo, Santiago: Ed. Ciudad Nueva, 1999, p. 450.

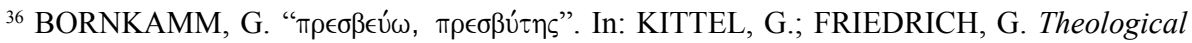
Dictionary of the New Testament. Volume VI. Michigan: WM. B. Eerdamans Publishing Company, 2006, pp. 651-683, p. 683.

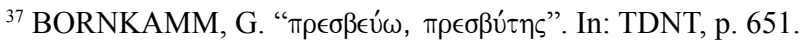


cooperador). Especialmente o adjetivo $\sigma u \nu \in \rho \gamma o ́ s$ indica uma relação de proximidade e anterioridade. Filemon não era apenas um conhecido ou amigo, mas um homem que comungava com o pensamento e com a proposta de Paulo. Sendo ele um colaborador ou participante da missão junto com Paulo, isso indica um bom convívio anterior, por isso as relações entre eles eram de estreito entendimento. Além disso, Filemon era um homem de amor e fé devotado ao Senhor Jesus e aos santos (v.5).

Paulo entende que amar os santos (apóstolos e mestres) e amar o Senhor era mais fácil do que amar os escravos e os subalternos. Usando o exemplo da $\kappa \in \nu \omega \sigma \iota \varsigma$ (Fl 2,5-8) de Jesus, Paulo pede um ato de generosidade maior a seu amigo. O amor para cima (aos santos e a Deus) deveria ser concomitante com o amor para baixo, para com escravos e marginalizados. Para tanto, Paulo se vale dessa ascendência natural sobre seu amigo e solicita com muita ternura esse novo olhar para baixo e para os lados.

\section{Paulo e a libertação pela compaixão: splanchna}

A Lei não produz os efeitos positivos esperados no campo da fé, do perdão e do amor; por isso, a razão deve ficar um pouco abaixo do coração, para que o coração possa sentir, conhecer e superar muitos esquemas externos e, antropologicamente, frios. A escravidão era um dos principais mecanismos de produção agrícola, artesanal e "industrial", pois tudo era movido pela força humana. Um escravo tinha um valor comercial calculado de acordo com a sua força de trabalho. Não se sabe se Onésimo deu prejuízo a Filemon só pela sua provável fuga ou se causou algum dano. Para manter os meios de produção, do ponto de vista legal o escravo não era considerado pessoa, mas apenas um instrumento a serviço do seu dono. Miguez faz um belo estudo sobre a situação dos escravos nas grandes cidades, especialmente no período do cristianismo primitivo. ${ }^{38}$ Contudo, é fundamental lembrar que a escravidão era homologada pelo próprio Decálogo (Ex 20,17; Dt 5,20).

Uma posição muito complexa e difícil de aceitar de Miguez é que Onésimo seria um "administrador do comerciante Filemon e, que enviado a Éfeso para tratar de assuntos de seu patrão, realizou mal seus negócios e perdeu o seu dinheiro" ${ }^{39}$ Essa apresentação de Onésimo como escravo e administrador

${ }^{38}$ MIGUEZ, N. “O Escravo e o Império Romano: o caso de Onésimo”. RIBLA 28 (1997/3), p. 93-96.

${ }^{39}$ MIGUEZ, N. “O Escravo e o Império Romano: o caso de Onésimo”, p. 98. 
é muito difícil. O administrador é sempre um associado, um partícipe nas negociações e goza sempre de direitos diferenciados dos escravos.

Paulo na pedagogia da libertação não usa a Lei, mas a compaixão. Jesus mostrou que a compaixão acontece por empatia e a ampliação dos sentimentos das entranhas onde todos os órgãos vibram e se conectam com a situação exterior como diante da viúva de Naim que estava sepultando o seu filho, sua única esperança $(\operatorname{Lc} 7,13)$, bem como o Samaritano diante do homem assaltado e machucado no caminho para Jericó (Lc 10,33) e o pai, que ao ver o filho esfarrapado que volta, se comove e sai ao seu encontro para abraçá-lo e beijá-lo (Lc 15,20). Nos três casos, Lucas utiliza o verbo $\sigma \pi \lambda \alpha \gamma \chi \nu i \zeta o \mu \alpha \iota$ que significa comover-se, sentir por dentro, ter empatia com a situação que se apresenta.

Na carta "pedido de libertação" a Filemon, Paulo usa três vezes (v. 7.12.20) o lexema $\sigma \pi \lambda \alpha^{\gamma} \gamma \chi \nu \alpha$ que, no sentido original, indica as partes interiores do ser em contraposição do seu exterior. No sentido cultual indica o âmago ou o coração da vítima sacrificada o qual era retirado e consumido pelos ofertantes. ${ }^{40} \Sigma \pi \lambda \alpha_{\alpha} \gamma \chi \nu \alpha$ é sempre um movimento das entranhas, do íntimo e por isso do interior do ser. Normalmente é entendido como o ato da compaixão, da misericórdia e da empatia de comunhão com uma situação exterior que faz o íntimo se comover. Não raro, estudiosos traduzem esse lexema por coração. Um caso emblemático é a narrativa do encontro de Jesus com a viúva de Naim, quando ele vê a viúva chorosa e o seu desespero por causa da morte de

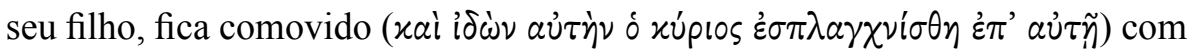
o fato e reanima a vida do jovem $(\operatorname{Lc} 7,13)$.

Paulo retém a exclusividade do uso de $\sigma \pi \lambda \alpha \dot{\gamma} \gamma \chi \nu \alpha$ no NT e o significado expressamente original do grau mais íntimo da reação humana quando manifesta um amor personalizado e profundo ${ }^{41}$.

O verso 7 se torna um ponto chave para o apelo de Paulo. Ele faz um belo elogio, afirmando que Filemon tem muita graça e conforto ( $\pi \alpha \rho \alpha ́ k \lambda \eta \sigma \iota \varsigma)$ e, no seu amor teve compaixão $\sigma \pi \lambda \alpha^{\prime} \gamma \chi \nu \alpha$ para com os santos. Esse elogio seria suficiente para Filemon sentir-se comprometido com qualquer coisa que pudesse vir ou qualquer apelo que lhe pudesse ser feito. Onésimo, cujas circunstâncias de encontro com Paulo e também a sua condição de vida junto a

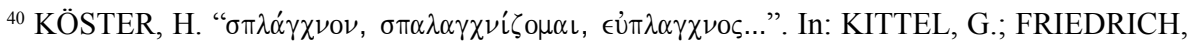
G. Theological Dictionary of the New Testament. Volume VI. Michigan: WM. B. Eerdamans Publishing Company, 2006, p. 548.

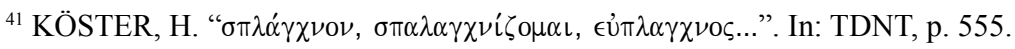


seu dono permanecem ainda bastante desconhecidas, precisava ser tratado de modo diferente, por causa do Evangelho.

De escravo à condição de filho, gerado na possível diaconia, na cadeia (v.13), parte Onésimo de volta para a casa de seu amo (v.10). O olhar de Filemon precisa mudar, mas mudar o olhar significava mudar os paradigmas da convivência. Não seria a Lei a determinar a mudança, mas a compaixão do coração, o movimento no âmago do ser. Paulo continua preso por causa do Evangelho (v.13), mas teve uma grande ajuda de um escravo, que agora já não é escravo, mas filho. A mudança processada por Paulo deve servir de exemplo para seu amigo Filemon no que concerne a Onésimo, por isso pede um gesto $\sigma \pi \lambda \alpha^{\prime} \gamma \chi \nu \alpha$ a Filemon, não mais voltado para o escravo, mas para o próprio Paulo, pois ele queria sentir seu íntimo, suas entranhas e seu coração vibrar de contentamento com essa mudança (v.20). Enquanto Filemon mudaria suas atitudes na direção de Onésimo, estaria alegrando o coração de Paulo. Como comenta Jerônimo, somos todos entranhas extraídas das entranhas da Igreja, somos entranhas espirituais, pois somos membros de um único corpo, a Igreja. ${ }^{42}$

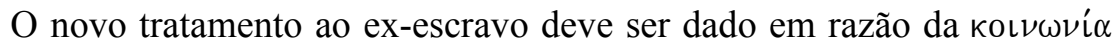
que Filemon tinha com Paulo e, logo, a recepção que ele dispensaria a seu mestre, agora precisaria dispensá-la a seu escravo. Uma grande mudança de

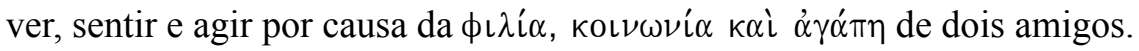

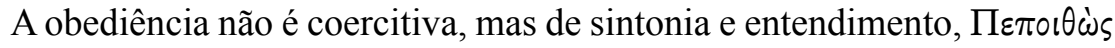

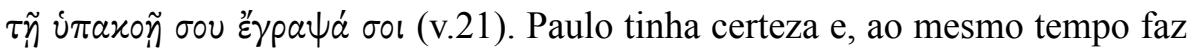
um elogio, pois está convencido de que seu amigo não faria apenas o que tinha recomendado, mas muito mais, por isso escreveu. Paulo usa a expressão $\pi \varepsilon \pi$ ol $\theta$ ஸ̀s que significa estar certo e convencido, portanto, a obediência não tem conotação de submissão, mas de adesão livre, de amor correspondente.

Mesmo não usando o título "apóstolo", o conteúdo da carta revela que Paulo estava agindo com toda a autoridade apostólica da qual ele se considerava investido e vocacionado (G1 1,1.11-12; 1Cor 1,1; 2Cor 1,1). ${ }^{43}$ É importante essa afirmação da autoridade implícita de Paulo, mas acompanhamos a carta muito mais em tom afetivo e fraterno do que em autoridade apostólica.

\footnotetext{
${ }^{42}$ GORDAY, P. "Filemon”, citando JERÔNIMO, Comentário a la Carta a Filemón, p. 459.

${ }^{43}$ WEGNER, U. “Comunidade e autoridade em Filêmon”. RIBLA 28 (1997/3), p. 83.
} 


\section{Os princípios humanistas de Paulo}

O fundamento do humanismo paulino está na própria pedagogia de Jesus. Paulo não cria e não inventa; ele entende, absorve e ensina numa linguagem própria para cada contexto da sua missão. Podemos definir como o princípio fundante a máxima de Paulo de que em Cristo caem todas as diferenças, preconceitos e segregações (Gl 3,28; cf. Rm 10,12; 1Cor 12,13; Cl 3,11).

A carta a Filemon é uma prova clara de que, conforme o Evangelho, Paulo entende a impossibilidade da escravidão. Não se trata apenas de uma questão de afeição, amizade ou empatia pessoal do Apóstolo com Onésimo, mas uma questão de princípios, depois que ele encontrou Jesus Cristo.

O ponto de partida é a dignidade na igualdade ou na isonomia sócio-político-religiosa. Nas culturas antigas e dentro do judaísmo pós-Esdras, as diferenças se tornaram maiores. A primeira foi entre judeus e samaritanos depois da morte de Salomão; a segunda, entre judeus e não judeus (no pós-exílio); a terceira, entre judeus e cristãos. Essas rupturas, no entanto, segundo Paulo, são incompatíveis com a pedagogia de Jesus Cristo e com o seu Evangelho. Toda diferença gera sofrimento e onde há sofrimento morre o Evangelho. Dessa forma, quer diferenças culturais, quer diferenças de gênero, quer diferenças de classes sociais, todas geram incluídos e excluídos, portanto rupturas que ferem a dignidade da pessoa humana. Onde a pessoa perde sua dignidade, aí entra o pecado, independentemente se por fatores culturais, políticos, econômicos ou religiosos.

Partindo do princípio da liberdade alcançada em Jesus Cristo, Paulo trabalha de modo incansável e inconfundível a favor da dignidade da pessoa, e, diante disso, precisa opor-se aos esquemas de privilégios e regalias, mesmo dentro das primeiras comunidades (cf. 1Cor 9,1-5). "É para a liberdade que Cristo nos libertou!" (G1 5,1). Essa liberdade é a condição da filiação a que todos têm direito pelo Espírito em Jesus Cristo (Rm 8,15). Os filhos, dentro da família, gozam dos mesmos privilégios e deveres uns para com os outros. Essa família não depende mais da relação de consanguinidade, nem da descendência, mas da prática da vontade do Pai (Mc 3,31-35). Até a criação fora submetida à vaidade do mundo e do pecado, mas em Cristo foi libertada da escravidão da corrupção, como se fosse uma criatura, para fazer parte da liberdade dos filhos de Deus (Rm 8,20-21). Paulo não sonhava apenas com uma libertação sociológica, mas com uma libertação integral do ser humano.

Uma libertação filosófica: Um texto que precisa ser bem entendido é 
1 Cor 7,21-24. Nessa orientação Paulo está mostrando o valor da liberdade, em Cristo, mesmo diante de paradoxos sociais. Os escravos poderiam aderir ao Evangelho sem uma preocupação antecipada de sua libertação político-social. As diferentes posições sociais não deveriam impedir de viver profundamente o Evangelho, pois uma busca de liberdade imediata poderia acarretar maiores conflitos ainda. Se alguém conheceu o Evangelho, na condição de escravo, poderia participar da comunidade cristã sem qualquer sentimento de segregação ou diferença (1Cor 11,17-34). O ideal era que ele pudesse participar sempre na condição de livre, mas, se o peso da estrutura fosse maior, ainda assim, sua presença na comunidade cristã deveria acontecer sem rupturas. Paulo sabia muito bem as circunstâncias nas quais a busca precipitada de liberdade através de tentativas de fuga poderia resultar em prejuízos maiores. Ele tinha clareza que a liberdade exterior e a interior devem ser construídas na maturidade, no compromisso mútuo e no amor. É preciso entender bem que Paulo não está sancionando a escravidão nessa orientação (1Cor 7,23), como, infelizmente afirma Ryan. ${ }^{44} \mathrm{O}$ que ele busca é minimizar os conflitos na Assembleia Cristã em detrimento das diferenças sociais que existem. A Ceia, como memorial do Senhor, não pode homologar as diferenças entre livres e escravos, entre doutos e ignorantes, entre ricos e pobres. O Evangelho se expressa na comunhão de pessoas e na corresponsabilidade radical no projeto de vida, independentemente da condição social. Todos estão chamados à liberdade, mas nem todos a conseguem sob o prisma sócio-político. $\mathrm{Na}$ assembleia, no entanto, essas diferenças precisam desaparecer, pois só o amor constrói $(1$ Cor 8,1$){ }^{45}$

$\mathrm{Na}$ carta a Filemon, Paulo tem a intenção de deixar claro ao seu amigo Filemon de que as coisas velhas das relações entre senhores e escravos estavam, de agora em diante, superadas de modo definivo, e ele, Filemon deveria olhar para Onésimo com outro olhar a partir do seu assumir a fé cristã. ${ }^{46}$

Paulo mostra quão importante é o Evangelho no quotidiano da vida. $\mathrm{O}$ Evangelho se relaciona diretamente com as questões sociais, políticas e culturais. Ainda que na estrutura social haja lugares e condições diferentes, à semelhança dos membros no corpo, com diversidade de dons e funções (1Cor 12,4-30), é importante entender o respeito, a dignidade e a imprescindibilidade de cada um no funcionamento total do corpo (físico, religioso ou políti-

\footnotetext{
${ }^{44}$ RYAN, J. M. Philippians and Philemon, p. 175.

45 MAZZAROLO, I. A primeira Carta de Paulo aos Coríntios. Rio de Janeiro: Mazzarolo editor, 2008, pp. 114-118.

${ }^{46}$ WEGNER, U. “Comunidade e autoridade em Filêmon”. RIBLA 28 (1997/3), p. 86.
} 
co-econômico). Nesse caso, a própria carta a Filemon não tem ainda a força de poder atacar de frente a escravidão, mas mostra sua ilogicidade diante do Evangelho. Dunn evidencia, na teologia de Paulo, as implicações entre Fé e Lei e a liberdade e o amor como deveres novos da conduta cristã, combatendo vícios e imoralidades, os quais destroem a justiça doméstica. ${ }^{47}$

Uma libertação integral: Se Onésimo tinha dado algum prejuízo a seu patrão Filemon, essa fato precisava ser superado e Paulo pede para colocar na conta dele (vv. 18-19), pois podia haver dois tipos de escravidão: a. A escravidão do poder econômico, dos bens e das propriedades, como no caso de Filemon; b. A escravidão sociológica e antropológica, como era o caso de Onésimo. O que Paulo fez com Onésimo, na prisão, foi a mudança na vida do escravo, agora por carta, tenta mudar a vida daquele que se considerava livre.

Diante do Evangelho não haveria mais privilégios ou vantagens em ser pagão ou ser judeu, todos agora necessitam de uma salvação que já não vem pela Lei, mas pela Fé e as obras da Fé. A libertação integral exigia também a superação do pecado, a superação dos esquemas de morte, dos vícios da carne e do revestimento de uma nova criatura em Cristo. ${ }^{48}$

A Lei não conseguiu realizar a verdadeira libertação de Israel, por isso todos necessitam da graça e da justiça ( $\operatorname{Rm} 9,30-33) .{ }^{49}$

Essa libertação exige a superação de muitos paradigmas arcaicos e caducos que faziam distinção entre culturas, posições sociais e religiões. Paulo retoma um princípio veterotestamentário, mas que havia sido deixado de lado no pós-exílio, para justificar a supremacia dos que retornavam da Babilônia: "Deus não faz acepção de pessoas" (Dt 10,17). Paulo retoma e dá novo sentido a essa máxima: "Pois não há distinção entre judeu e grego, uma vez que o mesmo é o Senhor de todos e rico para com todos os que o invocam. Porque todo aquele que invocar o nome do Senhor será salvo" (Rm 10,12-13).

Paulo defende uma libertação da letra morta, dos princípios superados e do fatídico olhar para trás em lugar de olhar para frente $(2 \mathrm{Cor} 3,6)$. O apego a letras (regras, rubricas, ritos arcaicos) mata toda a expectativa do novo, do belo e do atual. Paulo sabia bem que o conservadorismo religioso já era uma ideologia de manutenção do status quo, mas ele exortava à não conformação

\footnotetext{
${ }^{47}$ DUNN, J. D. G. A teologia do Apóstolo Paulo. São Paulo: Paulus, 2003, pp. 714-743.

${ }^{48}$ CAMBLIN, J. K. "Liberdade, Libertação". In: HAWTHORNE, G. F.; MARTIN, R. P.; REID, D. G. Dicionário de Paulo e suas Cartas. São Paulo: Vida Nova / Paulus / Loyola, 2008, pp. 797-800.

49 MAZZAROLO, I. Carta de Paulo aos Romanos, pp. 123-124.
} 
com um passado sem vida. Paulo tinha, provavelmente, consciência daquilo que mais tarde Mateus vai narrar como discurso de Jesus: "Ouvistes o que foi dito aos antigos?... Eu, porém, vos digo... (Mt 5,21-48).

\section{Conclusão}

A carta de Paulo a Filemon pode servir de paradigma para toda a Teologia do Apóstolo. Nas suas Igrejas e nas suas cartas percebemos como ele se empenhou na superação das mais diferentes formas de prisão: sociológica, ética, política, religiosa e cultural. O esforço para libertar Onésimo da escravidão sociológica era o mesmo que ele empenhava na libertação dos vícios, do pecado e das tradições superadas. Podemos afirmar que a Igreja de Paulo é includente. ${ }^{50}$

Paulo não admitia qualquer forma de diástole (separação, divisão) nas comunidades e afirmava que as diferenças eram motivo grave para a participação na Eucaristia sob risco de maldição $(1$ Cor 11,29). Ele precisou ser muito forte e corajoso diante de tantos preconceitos antigos que justificavam e homologavam práticas contrárias ao Evangelho. No helenismo, um princípio das Leis de Solon era de que a mulher, o escravo e a criança não eram cidadãos. $\mathrm{Na}$ tradição judaica as coisas não eram muito diferentes, pois nas redações da multiplicação dos pães, foram contados apenas os homens e não as mulheres e as crianças (cf. Mt 14,21; 15,38).

Nas Igrejas Paulinas entravam as mulheres, as crianças, os gentios e os judeus porque todos eram batizados no mesmo batismo e no mesmo Senhor (Ef 4,5). A pedagogia da inclusão na Teologia e Missão de Paulo se revela libertadora, promotora da vida nova em Cristo e da esperança de novos tempos (Rm 16).

\section{Referências bibliográficas}

BARBAGLIO, G. As cartas de Paulo II - Gálatas, Romanos, Filipenses e Filemon. São Paulo: Loyola, 1991.

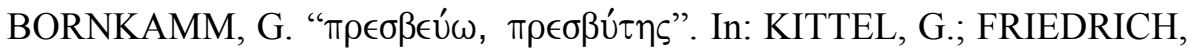
G. Theological Dictionary of the New Testament. Volume VI. Michigan: WM. B. Eerdamans Publishing Company, 2006, pp. 651-683.

\footnotetext{
${ }^{50}$ MAZZAROLO, I. O Apóstolo Paulo, o grego, o judeu e o cristão. Rio de Janeiro: Mazzarolo editor, ${ }^{2} 2011$, p. 181.
} 
BRUCE, F. F. The Epistles to the Colossians, to Philemon and to the Ephesians. Michigan: William B. Eerdmans Publishing Company, 1984.

CAMBLIN, J. K. "Liberdade, Libertação". In: HAWTHORNE, G. F.; MARTIN, R. P.; REID, D. G. Dicionário de Paulo e suas Cartas. São Paulo: Vida Nova / Paulus / Loyola, 2008, pp. 797-800.

COMBLIN, J. “A Mensagem da Epístola de São Paulo a Filemon”. Estudos Bíblicos 2 (1987), pp. 50-70.

DUNN, J. D. G. A teologia do Apóstolo Paulo. São Paulo: Paulus, 2003.

GORDAY, P. "Filemon". In: GORDAY, P. (Org.). Colossenses, 1-2 Tessalonicenses, 1-2 Timoteo, Tito, Filemón. La Biblia Comentada por los Padres de la Iglesia. Volume 9. Madrid, Bogotá, Buenos Aires, Montevideo, Santiago: Ed. Ciudad Nueva, 1999, pp. 449-451.

HARRILL, J. A. "Paulo e a escravidão". In: SAMPLEY, J. P. Paulo no mundo Greco-Romano, um compêndio. São Paulo: Paulus, 2008, pp. 505-534.

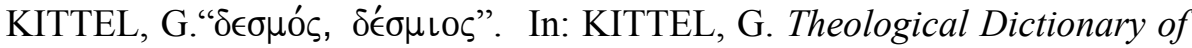
the New Testament. Volume II. Michigan: WM. B. Eerdmans Publishing Company, 2006, p. 43.

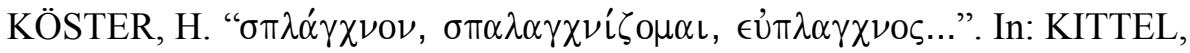
G.; FRIEDRICH, G. Theological Dictionary of the New Testament. Volume VI. Michigan: WM. B. Eerdamans Publishing Company, 2006, pp. 548-559.

MAZZAROLO, I. Lucas, a antropologia da Salvação. Rio de Janeiro: Mazzarolo editor, 2004.

MAZZAROLO, I. Carta de Paulo aos Romanos. Rio de Janeiro: Mazzarolo editor: 2006.

MAZZAROLO, I. A primeira Carta de Paulo aos Coríntios. Rio de Janeiro: Mazzarolo editor, 2008.

MAZZAROLO, I. Filemon, a Carta da Alforria. Rio de Janeiro: Mazzarolo editor, 2011.

MAZZAROLO, I. O Apóstolo Paulo, o grego, o judeu e o cristão. Rio de Janeiro: Mazzarolo editor, ${ }^{2} 2011$.

MIGUEZ, N. "O Escravo e o Império Romano: o caso de Onésimo". RIBLA 28 (1997/3), pp. 90-98. 
OSIEK, C. Philippians and Philemon. Nashville: Abingdon Press, 2000.

RAPSKE, B. Paul in Roman Custody. The Book of Acts in its First Century Setting. Volume 3. Michigan: William B. Eerdmans Publishing Company, 1994.

RUPRPECHT, A. "Philemon". In: THE EXPOSITOR'S BIBLE COMMENTARY WITH THE NEW INTERNATIONAL VERSION. Ephesians trough Philemon. Michigan: Zondervan, 1981.

RYAN, J. M. "Philemon”. In: THURSTON, B. B.; RYAN, J. M.; JUDITH, M. Philippians \& Philemon. Minessota: D. J. Harrington editor, 2004.

VIELHAUER, P. História da literatura cristã primitiva; introdução ao Novo Testamento, aos apócrifos e aso pais apostólicos. Santo André: Academia Cristã, 2005.

WEGNER, Uwe. "Comunidade e autoridade em Filemon". RIBLA 28 (1997/3), pp. 83-89.

Isidoro Mazzarolo

Doutor em Teologia Bíblica pela Pontifícia Universidade Católica do Rio de Janeiro Professor no Instituto Franciscano de Petrópolis / RJ Professor na Pontifícia Universidade Católica do Rio de Janeiro Rio de Janeiro / RJ - Brasil E-mail: mazzarolo.isidoro@gmail.com

Recebido em: 08/09/16 Aprovado em: 16/11/16 